\title{
A WRF simulation of the impact of 3-D radiative transfer on surface hydrology over the Rocky Mountains and Sierra Nevada
}

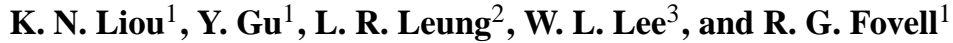 \\ ${ }^{1}$ Joint Institute for Regional Earth System Science and Engineering, Department of Atmospheric and Oceanic Sciences, \\ University of California, Los Angeles, CA 90095, USA \\ ${ }^{2}$ Pacific Northwest National Laboratory, Richland, WA, USA \\ ${ }^{3}$ Research Center for Environmental Changes, Academia Sinica, Taipei, Taiwan
}

Correspondence to: Y. Gu (gu@atmos.ucla.edu)

Received: 3 July 2013 - Published in Atmos. Chem. Phys. Discuss.: 23 July 2013

Revised: 18 October 2013 - Accepted: 22 October 2013 - Published: 3 December 2013

\begin{abstract}
We investigate 3-D mountains/snow effects on solar flux distributions and their impact on surface hydrology over the western United States, specifically the Rocky Mountains and Sierra Nevada. The Weather Research and Forecasting (WRF) model, applied at a $30 \mathrm{~km}$ grid resolution, is used in conjunction with a 3-D radiative transfer parameterization covering a time period from 1 November 2007 to 31 May 2008, during which abundant snowfall occurred. A comparison of the 3-D WRF simulation with the observed snow water equivalent (SWE) and precipitation from Snowpack Telemetry (SNOTEL) sites shows reasonable agreement in terms of spatial patterns and daily and seasonal variability, although the simulation generally has a positive precipitation bias. We show that 3-D mountain features have a profound impact on the diurnal and monthly variation of surface radiative and heat fluxes, and on the consequent elevationdependence of snowmelt and precipitation distributions. In particular, during the winter months, large deviations (3-D$\mathrm{PP}$, in which PP denotes the plane-parallel approach) of the monthly mean surface solar flux are found in the morning and afternoon hours due to shading effects for elevations below $2.5 \mathrm{~km}$. During spring, positive deviations shift to the earlier morning. Over mountaintops higher than $3 \mathrm{~km}$, positive deviations are found throughout the day, with the largest values of $40-60 \mathrm{~W} \mathrm{~m}^{-2}$ occurring at noon during the snowmelt season of April to May. The monthly SWE deviations averaged over the entire domain show an increase in lower elevations due to reduced snowmelt, which leads to a reduction in cumulative runoff. Over higher elevation areas, positive SWE deviations are found because of increased solar radiation available
\end{abstract}

at the surface. Overall, this study shows that deviations of SWE due to 3-D radiation effects range from an increase of $18 \%$ at the lowest elevation range $(1.5-2 \mathrm{~km})$ to a decrease of $8 \%$ at the highest elevation range (above $3 \mathrm{~km}$ ). Since lower elevation areas occupy larger fractions of the land surface, the net effect of 3-D radiative transfer is to extend snowmelt and snowmelt-driven runoff into the warm season. Because $60-90 \%$ of water resources originate from mountains worldwide, the aforementioned differences in simulated hydrology due solely to 3-D interactions between solar radiation and mountains/snow merit further investigation in order to understand the implications of modeling mountain water resources, and these resources' vulnerability to climate change and air pollution.

\section{Introduction}

The spatial orientation and inhomogeneous features of mountains/snow interact with direct and diffuse solar beams in an intricate manner. Quantifying these interactions and reliably determining total surface solar fluxes for incorporation in a land-surface model is a challenging task that has yet to be accomplished in regional and global climate modeling. Virtually all current climate models have used a plane-parallel (PP) radiative transfer program to perform radiation parameterization, and the potential errors have never been quantified. 
In conjunction with radiative transfer in mountains/snow regions, we have developed a Monte Carlo photon tracing program, which is specifically applicable to intense and complex inhomogeneous mountains. We demonstrate that the effect of mountains on surface radiative balance is substantial in terms of subgrid variability as well as domain average conditions; a significant solar flux deviation of $\sim 10-35 \mathrm{~W} \mathrm{~m}^{-2}$ from the plane-parallel radiation parameterization of conventional climate models would occur if realistic mountain features were accounted for in surface energy modeling (Chen et al., 2006; Liou et al., 2007; Lee et al., 2011, 2012). Because of the computational burden required by the 3-D Monte Carlo photon tracing program, an innovative parameterization approach in terms of deviations from the PP radiative transfer results, which are readily available in climate models, was developed for the five components of surface solar flux: direct and diffuse fluxes, direct- and diffuse-reflected fluxes, and coupled flux, which involves mountain interactions (Lee et al., 2011). In the development of 3-D radiation parameterization in terms of deviations from PP results, we adopted the mean values for the sky view factor, the terrain configuration factor, the cosine of the solar zenith angle, and conventional topographic parameters for a preselected $10 \mathrm{~km} \times 10 \mathrm{~km}$ domain (involving mean elevation and slope in multiple linear regression analysis, along with their standard deviations and skewness). We used a rugged area of the Sierra Nevada as an experimental testbed for this development (Lee et al., 2011). Five regression equations for flux deviations, which are linear and have a general $5 \times 5$ matrix form, have been derived. The flux components computed from Monte Carlo simulations were used to assess the accuracies of multiple regression analysis results for the five flux components, along with multiple determination coefficients, $R^{2}$, with a number of surface albedos. The most significant term is the direct flux, which generally has high correlations of $>0.9$ with root mean square errors less than $3 \mathrm{~W} \mathrm{~m}^{-2}$ (out of $700 \mathrm{~W} \mathrm{~m}^{-2}$ ). Deviations from plane-parallel results are on the order of $100 \mathrm{~W} \mathrm{~m}^{-2}$. For other flux components, $R^{2}$ ranges between $0.6-0.9$ and deviations are on the order of a few $\mathrm{W} \mathrm{m}^{-2}$.

The preceding 3-D radiative transfer parameterization was incorporated into the Weather Research and Forecasting (WRF) model (Skamarock et al., 2005) to investigate and understand the impact of the spatial and temporal distribution and variation of surface solar fluxes on land-surface processes ( $\mathrm{Gu}$ et al., 2012). The model domain selected for the study was the Sierra Nevada, a mountain range that is centered at $35^{\circ} \mathrm{N}-120^{\circ} \mathrm{W}$ and covers the area from 135$105^{\circ} \mathrm{W}$ and $20-45^{\circ} \mathrm{N}$. $48 \mathrm{~h}$ model integrations have been performed starting on 29 March 2007, at 00:00 UTC. We showed that the mountain effect could produce deviations in downward surface solar fluxes as large as -50 to $+50 \mathrm{~W} \mathrm{~m}^{-2}$ over mountain areas, resulting in a temperature increase of up to $1^{\circ} \mathrm{C}$ on the sunnier side. Surface sensible and latent heat fluxes are modulated accordingly to compensate for the change in surface solar fluxes. Snow water equivalent (SWE) and surface albedo both show decreases on the sunny side of the mountains, indicating more snowmelt and hence reduced snow albedo associated with more solar insolation due to the mountain effect. The daily averaged deviations in surface solar flux are positive over the mountain areas and negative in the valleys, exhibiting a range between -12 and $+12 \mathrm{~W} \mathrm{~m}^{-2}$. Differences in the domain-averaged diurnal variation over the Sierra Nevada illustrate that mountain areas receive more solar flux in the early morning and late afternoon, resulting in enhanced sensible heat and latent heat fluxes from the surface, and a corresponding increase in surface skin temperature.

In this paper, we investigate the longer-term effect of 3-D radiative transfer over mountains/snow in the western United States covering both the narrow coastal Sierra Nevada and the broad continental Rocky Mountains. Marked by complex terrain, and a surface hydrology dominated by seasonal precipitation and snow accumulation and melt (e.g., Leung et al., 2003a, b), the western United States presents an interesting region to study the effects of 3-D radiation on the surface energy and water balance. The surface hydrology of the region has been shown to be sensitive to climate change (Leung et al., 2004; Kapnick and Hall, 2010) and aerosol deposition in snowpack (Qian et al., 2009). Thus, understanding the factors leading to uncertainties in modeling snowpack and runoff is important for improving hydrologic predictions from seasonal to century time scales. We present pertinent simulation results in terms of deviations (3-D-PP) of surface solar fluxes and their impact on a number of surface parameters from 1 November 2007 to 31 May 2008, during which abundant snowfall occurred. We focus our analysis on the complex terrains ranging from $1.5 \mathrm{~km}$ to above $3 \mathrm{~km}$, which are grouped into four elevation zones.

The organization of the present study is as follows. In Sect. 2, we describe the WRF model used in this investigation, followed by a discussion in Sect. 3 on comparison of 3-D simulation results with available observations for SWE and precipitation. In Sect. 4, we discuss the significance of 3-D radiation effect on the diurnal, monthly, and elevation variation in solar flux, sensible and latent heat fluxes, and surface skin temperature. We do likewise for the monthly averaged surface fluxes, cloud water path, SWE, precipitation, and runoff. Concluding remarks are given in Sect. 5.

\section{3-D Radiation parameterization in a WRF model}

To study the longer term effect of 3-D radiation over mountains/snow, we have employed the WRF model version 3.4 (Skamarock et al., 2008). The relevant model components include the Noah land-surface model (LSM), which is a 4-layer soil temperature and moisture model that predicts canopy moisture and snow cover (Chen and Dudhia, 2001), MM5 surface layer scheme (Paulson, 1970; Dyer and Hicks, 1970; 
Webb, 1970; Beljaars, 1994; Zhang and Anthes, 1982), Lin scheme for microphysics (Lin et al., 1983), Kain-Fritsch cumulus scheme (Kain and Fritsch, 1990, 1993), and YSU scheme for planetary boundary layer (Hong et al., 2006). For snow-covered surfaces, the Noah LSM considers a mixed snow-vegetation-soil layer and simulates the snow accumulation, sublimation, melting, and heat exchange at the snowatmosphere and snow-soil interfaces using a simple snow parameterization developed by Koren et al. (1999). The 3$D$ radiation parameterization follows the approach presented above, which was used in connection with the Fu-Liou-Gu plane-parallel radiation scheme (Fu and Liou, 1992, 1993; Gu et al., 2010, 2011); this scheme has been included in the WRF physics package.

We have selected a domain covering the Rocky Mountains and Sierra Nevada in the western United States, which is centered at $35^{\circ} \mathrm{N}-120^{\circ} \mathrm{W}$ and covers the area from 135$102.5^{\circ} \mathrm{W}$ and $20-45^{\circ} \mathrm{N}$. The horizontal grid resolution is 30 $\mathrm{km}$, and the vertical resolution has 28 model levels, the same as discussed in Sect. 1. Initial and boundary conditions are provided by the National Centers for Environmental Prediction (NCEP) Final (FNL) Operational Global Analysis available from the Global Forecast System (GFS) every $6 \mathrm{~h}$ on $1.0 \times 1.0$ degree grids. Model integrations have been performed for a period of 7 months, starting on 1 November 2007 at 00:00 UTC and ending on 31 May 2008. This period was selected because the observed snowpack was above the climatological average during this time, enabling us to assess the effect of 3-D radiative transfer on surface hydrology during a wet year. To investigate the impact of 3-D mountains on surface insolation and snow budget over the Rocky Mountains and Sierra Nevada regions, we have designed the following two experiments. The PP experiment was the control run in which the Fu-Liou-Gu radiation scheme was used for $\mathrm{PP}$ radiative transfer calculations, whereas the 3-D experiment was identical to PP, except that the parameterization for 3-D solar flux deviations over the Rocky Mountains and Sierra Nevada areas was implemented within the Fu-Liou$\mathrm{Gu}$ radiation scheme. Figure 1 displays the elevation map over a $30 \mathrm{~km}$ resolution grid for the Rocky Mountains and Sierra Nevada areas in the western United States. The box on the map shows major mountainous areas where simulation results are analyzed.

\section{Comparison with observations: SWE and precipitation}

The spatial and temporal distributions of surface solar radiation are the primary energy sources that contribute to the energy and water balance at the 3-D and inhomogeneous mountain surface, particularly the snowmelt (Geiger, 1965; Bonan, 2002; Gu et al., 2002; Müller and Scherer, 2005). Figure $2 \mathrm{~b}$ depicts a map of the monthly mean SWE (ranging from 5-1200 mm) for April 2008, simulated from the
Terrain Height (m): 30 × $30 \mathrm{~km}^{2}$ Resolution

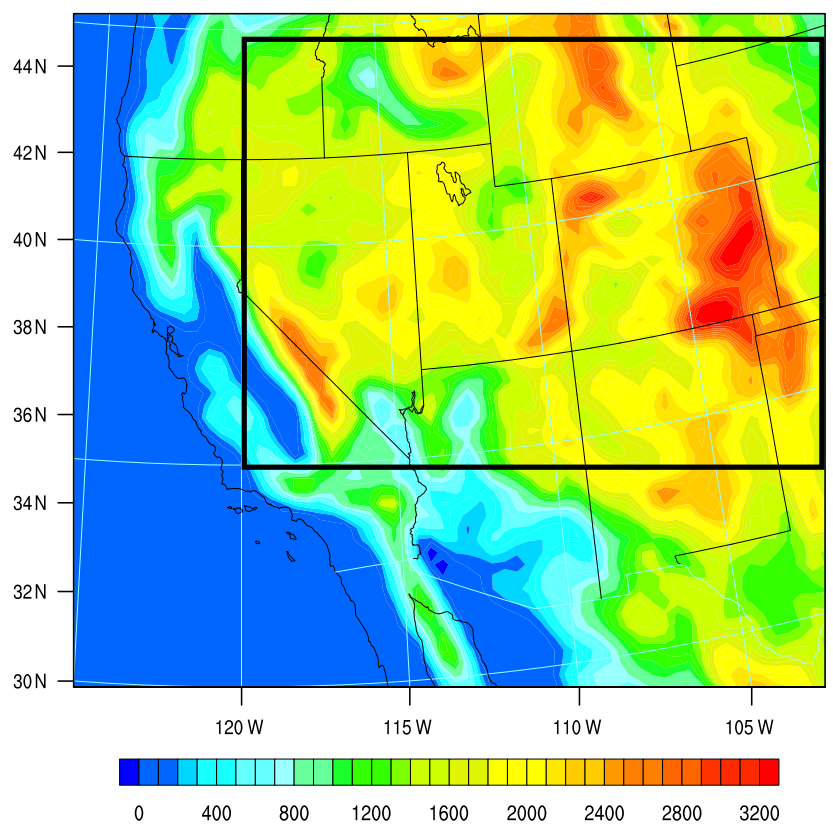

Fig. 1. The elevation map over a $30 \mathrm{~km}$ resolution grid for the Rocky Mountains and Sierra Nevada areas in the western United States. The box on the map displays major mountainous areas where simulation results are analyzed and presented in the paper.

WRF with the inclusion of 3-D radiation parameterization for mountains/snow. The simulation SWE results are seen over the vast Rocky Mountains region and, to a lesser degree, over the Sierra Nevada to the west. The SWE pattern shows relatively smaller values at the highest elevation in response to the reduced precipitation and the largest solar flux available at mountaintops. The 3-D mountain shading effect also plays a pivotal role in reducing the solar flux availability at some lower-elevation areas, resulting in more SWE accumulation in these areas.

Figure 2c shows the monthly mean SWE values estimated from the Northern Hemisphere daily snow depth analysis data processed by the Canadian Meteorological Centre (CMC) (Brown and Brasnett, 2010) at a spatial resolution of $24 \mathrm{~km}$, which is comparable to the WRF simulations at $30 \mathrm{~km}$ grid resolution. The CMC data clearly display SWE over the Rocky Mountains and Sierra Nevada regions. The simulated WRF results show a similar spatial pattern to CMC, but have SWEs that are larger than the observations in terms of both the magnitude and areal coverage. We also compared the monthly time series of SWE for the study domain for two elevation zones of $2.5-3 \mathrm{~km}$ and $>3 \mathrm{~km}$ (Fig. $2 \mathrm{~d}$ ) with the results presented in Rasmussen et al. (2011) (Fig. 2e) for the same cold season (starting in November 2007). The black dots in Fig. 2e denote the SWE measurements collected at Snowpack Telemetry (SNOTEL) stations (typically between 
Snow Water Equivalent (SWE, mm)
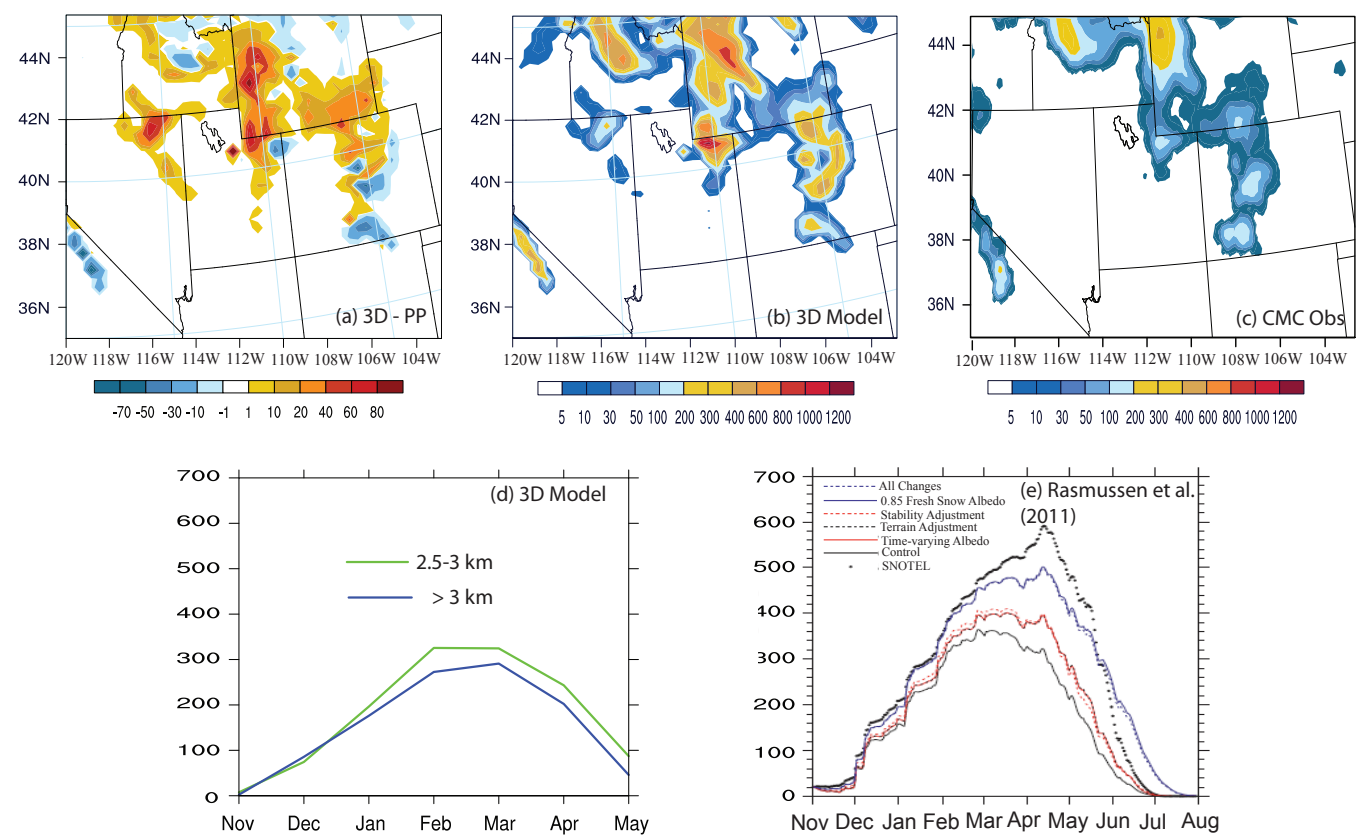

Fig. 2. (a) The monthly mean SWE deviation (3-D-PP) map. (b) The monthly mean SWE map (5-1200 mm, see Fig. 1) for April 2008 simulated from the WRF with the inclusion of 3-D radiation parameterization. (c) The monthly mean SWE values estimated from the Northern Hemisphere daily snow depth analysis data processed by the Canadian Meteorological Centre (CMC). (d) The monthly time series of SWE for the study domain for two elevation zones of $2.5-3 \mathrm{~km}$ and $>3 \mathrm{~km}$. (e) The monthly time series of SWE presented in Rasmussen et al. (2011). The black dots denote the SWE measurements collected at stations that are typically between 2.4 and $3.6 \mathrm{~km}$ in Colorado.

2.4 and $3.6 \mathrm{~km}$ in Colorado), and the various curves correspond to WRF simulations performed at a $4 \mathrm{~km}$ resolution with various adjustments and averaged over all the SNOTEL locations. Our results at the two elevation zones, simulated by the WRF at a $30 \mathrm{~km}$ resolution with 3-D radiation parameterization, are smaller than the observed SNOTEL data and the results of $4 \mathrm{~km}$ resolution WRF simulations. Considering the fact that no specific changes have been made to the WRF model for our simulations, as well as the coarser spatial resolution in our study, our results are in reasonable agreement with the control simulation displayed in Fig. 2e. Additionally, we have included contours of differences (3-D-PP) in the simulated SWE (Fig. 2a). In comparison with CMC observations, WRF model results tend to produce larger SWE values over mountain areas. As shown, the incorporation of 3-D radiation parameterization has reduced model overestimation in reference to PP results to certain degree. However, the model overestimation bias involving SWE can come from a number of sources, including snow parameterization and precipitation bias, and cannot be solely resolved by 3-D radiation parameterization.

Moreover, we compared the domain-averaged monthly cumulative precipitation from the 3-D simulation for two elevation zones of $2.5-3 \mathrm{~km}$ and $>3 \mathrm{~km}$ with the Parameter-elevation Regressions on Independent Slopes
Model (PRISM) data (Daly et al., 1994; Taylor et al., 1997), which are average results determined from cumulative precipitation measured by 112 SNOTEL sites (Fig. 3a). These sites provide a long-term record of precipitation at high elevations from gauges across the western United States. The cumulative precipitation increases from November to May, with more precipitation accumulated between December and February. The $30 \mathrm{~km}$ resolution model results are larger than, but consistent with, the PRISM values. The daily precipitation time series (0-240 days) from the 3-D simulation is displayed in Fig. 3b, along with the PRISM data. Again, the results reveal that the model reproduced the observed daily variability quite well, but is consistently larger than the PRISM data. Note that our simulations employed the Lin microphysics parameterization, whereas Rasmussen et al. (2011) used the Thompson microphysics parameterization. Thus, differences between the two simulations could be related to microphysics parameterizations in addition to model resolutions. Overall, however, our simulations capture key features of the daily and seasonal variability as well as the spatial pattern of precipitation and snowpack, which provides confidence in our analysis of the impacts of 3-D radiation effects on surface hydrology. 

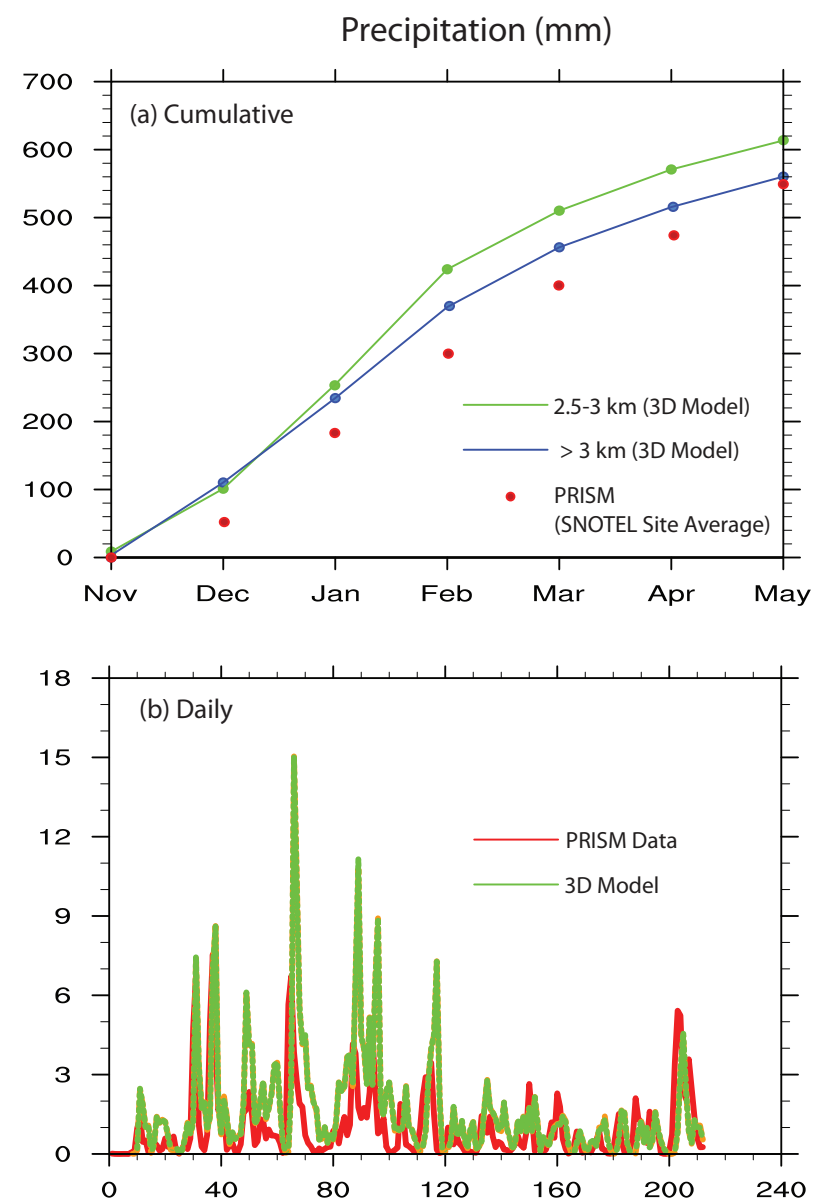

Fig. 3. (a) The domain-averaged monthly cumulative precipitation simulated from the present model for two elevation zones $(2.5-3 \mathrm{~km}$ and $>3 \mathrm{~km}$ ) with the Parameter-elevation Regressions on Independent Slopes Model (PRISM) data, which are the averaged results determined from cumulative precipitation measured from 112 SNOTEL sites. (b) The daily precipitation time series (0-240 days) computed from the 3-D model, along with the PRISM data.

\section{Discussions of the 3-D radiation impacts on simulation results}

\subsection{Diurnal/monthly/elevation variation}

The diurnal variation of downward surface solar flux over mountain areas is critically important to regional weather and climate predictions. Figure 4 illustrates simulated deviations in the monthly averaged downward solar flux at the surface (3-D-PP) for 08:00, 12:00, and 17:00 local time in April 2008. The spatial and temporal variations of surface solar flux over the Rocky Mountains and Sierra Nevada regions are determined by the position of the Sun. The averaged solar zenith angles for the month of April corresponding to the three local times are also depicted in the figure. In the early morning, sunlight comes from the east, and posi- tive deviations are shown on the southeast side of the mountains, while negative values are located in the northwest region. At noon, positive deviations are mostly located south of $38^{\circ} \mathrm{N}$ and on mountaintops, while negative values are seen north of the mountains, especially in valley areas. In the late afternoon, the opposite conditions occur; increases in solar flux are located in the southwest of the mountains, while decreases in solar flux are found in the northeast region. Solar flux deviations at each grid box are affected by surrounding mountains through 3-D radiation parameterization using a $1 \mathrm{~km}$ subgrid topographic data and the averaged solar zenith angle. For the north-south oriented mountains (e.g., the Sierra Nevada: $118-120^{\circ} \mathrm{W}, 36-38^{\circ} \mathrm{N}$ ), positive/negative deviations are generally found on the mountain's east/west sides in the morning (Fig. 4a), and its west/east sides in the afternoon (Fig. 4c). These deviations are distributed over the mountains and surrounding regions at noon (Fig. 4b). For west-east oriented mountains (e.g., $112-115^{\circ} \mathrm{W}, 44^{\circ} \mathrm{N}$ ), positive deviations are primarily located at the mountain's south slope. Also, the solar zenith angle has an impact on the latitudinal distribution of solar flux deviations. Because less solar fluxes are available at high latitudes, solar flux deviations due to the 3-D mountain effect are smaller. However, positive/negative patterns are primarily dependent on mountain orientation and elevation.

Deviations (3-D-PP) in the monthly mean domainaveraged diurnal variation time series of downward surface solar flux for a number of elevation ranges, including 1.5$2 \mathrm{~km}$ (red), 2-2.5 km (orange), 2.5-3 m (green), above $3 \mathrm{~km}$ (blue), as well as the whole domain (black), over the Rocky Mountains and Sierra Nevada areas are shown in Fig. 5 for 6 months (December 2007 to May 2008). Flat lines denote nighttime, during which solar insolation is zero. During the winter months (December 2007-February 2008), positive deviations in the surface solar flux are found in the morning (07:00-10:00) and afternoon (14:00-17:00), while negative deviations are shown between 10:00-14:00 for lower elevations (below $2.5 \mathrm{~km}$ ). For the higher elevation of $2.5-3 \mathrm{~km}$, the negative-deviation regions only occur in February. The maximum negative deviation occurs in the lower elevation $(1.5-2 \mathrm{~km})$ around noon in February, with a value on the order of $30 \mathrm{~W} \mathrm{~m}^{-2}$ produced by the 3-D mountain effect. During the spring (March-May 2008), positive deviations shifts to earlier morning (06:00-08:00) while negative deviations begin to occur at 08:00. Negative deviations become smaller in magnitude at noontime because of overhead sunlight, which reduces the shading effect. Starting in April, positive deviations are seen around noon, in addition to those in the early morning and later afternoon, leading to larger diurnal variations during the day. Over the mountaintops (above $3 \mathrm{~km}$ ), positive deviations are found throughout the day, indicating that more solar fluxes are available in this region due to the 3-D mountain effect. The maximum positive deviation is found around noon in May with a value of $\sim 60 \mathrm{~W} \mathrm{~m}^{-2}$, which is $\sim 6 \%$ of the downward solar flux at the time. The 
Downward Surface Solar Flux Deviations (3D - PP)
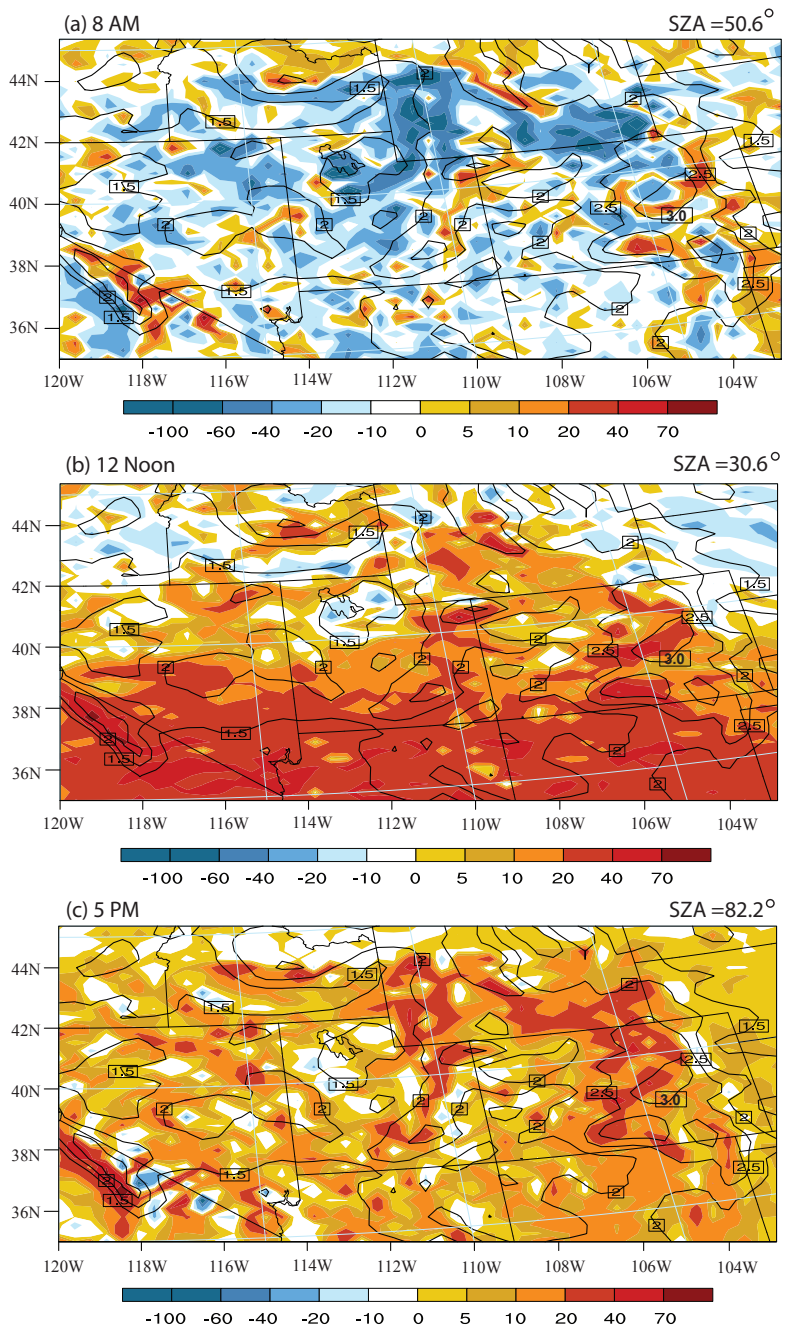

Fig. 4. Deviations (3-D-PP) in the monthly averaged downward surface solar flux distributions in $\mathrm{W} \mathrm{m}^{-2}$ for $8 \mathrm{AM}, 12$ noon, and $5 \mathrm{PM}$ local time in April 2008 (see the box in Fig. 1). The solar flux scale ranges from -100 to $+70 \mathrm{~W} \mathrm{~m}^{-2}$. Also shown are elevation height contours of $1.5,2,2.5$, and $3 \mathrm{~km}$.

domain averaged variation is basically dominant at the lower elevations (below $2.5 \mathrm{~km}$ ), which comprise $\sim 65 \%$ of the domain area in the current analysis. The available surface solar flux increases from December to May at any given time of the day, resulting in enhanced deviations (3-D-PP) induced by shading and elevation effects.

Moreover, it should be pointed out that the flux deviation (3-D-PP) at each model grid box is affected by surrounding mountains via $3-D$ radiation parameterization using the solar zenith angle and $1 \mathrm{~km}$ topographic data as the building block. In the parameterization, the sky view factor and the terrain configuration factor are used to represent the distance and height of nearby mountains with respect to a target point at a given solar zenith angle. An unobstructed horizontal surface will intercept radiation emitted from the sun in all directions. Over mountainous areas, however, the solar fluxes intercepted at a target point are subject to being blocked by surrounding mountains. Consequently, only a portion of the sky dome can be visible at the target point, which is defined by the sky view factor, representing the shadow effect of mountains on the direct and diffuse solar fluxes reaching the target point. The terrain configuration factor is defined as the area of surrounding mountains visible at the target point, which determines the portion of solar fluxes that is reflected to the target point from surrounding mountains. This parameter will affect the direct- and diffuse-reflected fluxes as well as the coupled flux induced by mountain topography.

Increases or decreases in the surface downward solar radiation affect latent and sensible fluxes, leading to surface skin temperature variation, all of which are displayed in Figs. 6 8. Changes in the seasonal sensible and latent heat fluxes as functions of local time and elevation - basically follow the patterns of solar flux presented above. However, negative (winter) and positive (spring) deviations become smaller in magnitude around noon. The sensible heat flux is generally greater than the latent heat flux associated with temperature and water vapor gradients in mountain areas. For example, in May, we see a maximum of $\sim 30 \mathrm{~W} \mathrm{~m}^{-2}$ around noon for sensible heat flux compared to $\sim 10 \mathrm{~W} \mathrm{~m}^{-2}$ for latent heat flux. Deviations in the surface skin temperature largely match the diurnal time series patterns in surface solar fluxes during winter and spring. The surface skin temperature displays cooling for lower elevations $(<2.5 \mathrm{~km})$ produced by the 3-D mountain effect (except during the daytime in May). In mountaintop regions (>3 km), warming is found throughout the day for both winter and spring, the degree of which is dependent on the mean solar zenith angle and sunlight hour. The surface temperature deviation ranges between -0.3 and $+0.3 \mathrm{~K}$, except in May, during which surface temperature varies from 0.3 to $1.2 \mathrm{~K}$.

\subsection{Monthly averaged surface fluxes, CWP, SWE, precipitation, and runoff}

The monthly averaged downward solar flux map for April 2008 simulated for the 3-D case as a function of latitude and longitude is shown in Fig. 9a. The corresponding deviations (3-D-PP) are displayed in Fig. 9c. Because of the cancellation of opposite deviations on the two sides of mountains during morning and afternoon hours, solar flux is enhanced broadly on the south-facing side of the mountains south of $38^{\circ} \mathrm{N}$ and reduced on the north- facing side northward of $38^{\circ} \mathrm{N}$. In addition, larger increases in solar flux due to the 3-D effect are mainly found over mountaintops. Larger reductions, on the other hand, are mostly observed over valley areas between $40-44^{\circ} \mathrm{N}$ and west of $110^{\circ} \mathrm{W}$, where mountains are located in the south and the east. Changes in the surface downward solar flux distribution can affect the 
Surface Solar Flux (3D - PP, W m $\left.{ }^{-2}\right)$
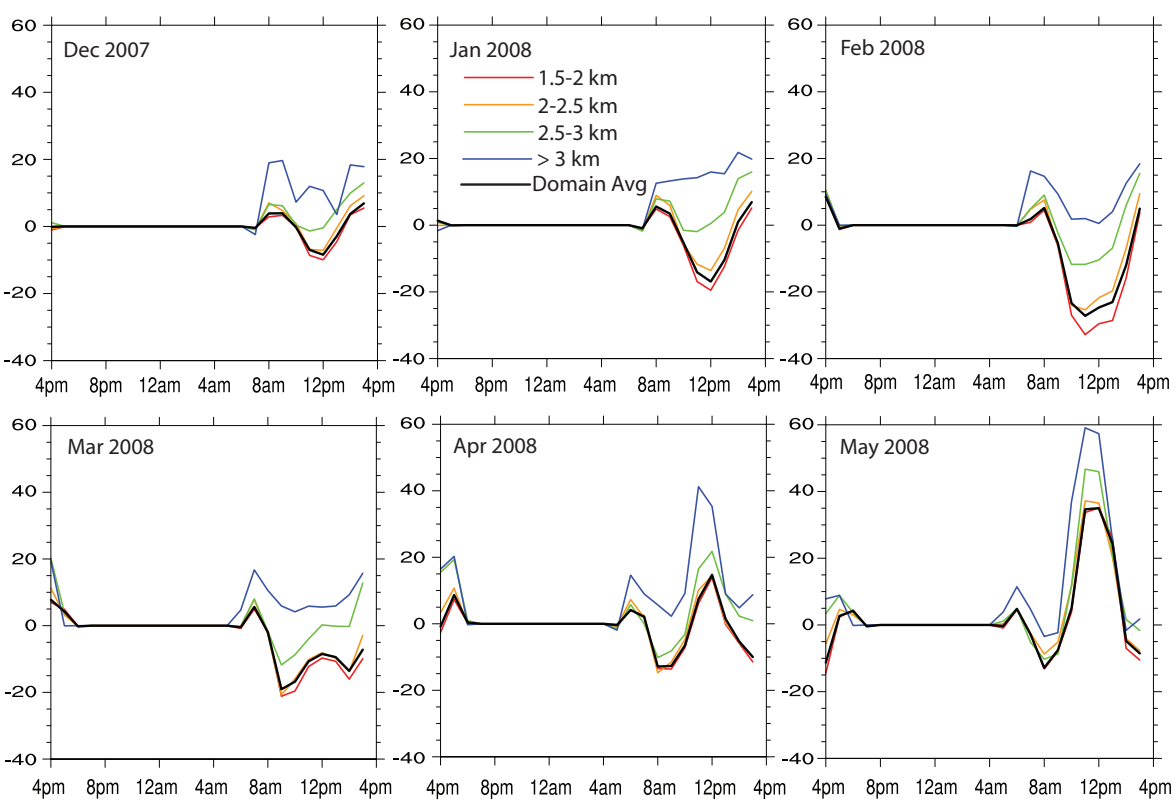

Fig. 5. Deviations (3-D-PP) in the monthly mean domain-averaged diurnal variation time series of surface solar flux for a number of elevation ranges, including 1.5-2 km (red), 2-2.5 km (orange), 2.5-3 m (green), above $3 \mathrm{~km}$ (blue), as well as the whole domain (black), over the Rocky Mountains-Sierra Nevada area for 6 months (December 2007 to May 2008). Flat lines denote nighttime, during which solar insolation is zero.
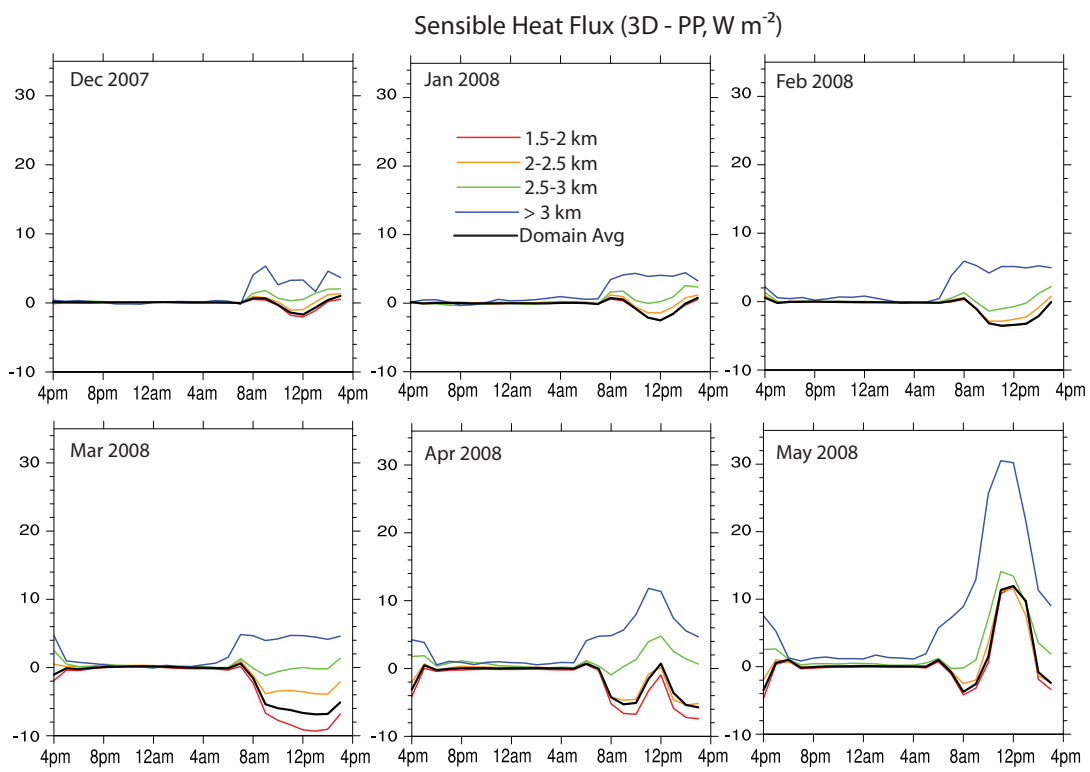

Fig. 6. Same as in Fig. 5, except for the monthly mean domain-averaged diurnal variation time series of sensible heat flux.

formation of clouds, which in turn will impact the transfer of solar flux reaching the surface. Thus, we also examine cloud water path (CWP) produced from experiments 3-D and PP for April 2008. Figure $9 \mathrm{~b}$ shows the CWP distributions, while Fig. 9d displays deviations (3-D-PP). In reference to Fig. 9d, CWP increases over the mountain summits in the vicinity of northern Rocky Mountains where downward solar radiation increases (Fig. 9c), which can enhance the upslope flow and convection, leading to more cloud formation. The increased CWP will in turn partially offset the increased solar radiation over mountaintops. 

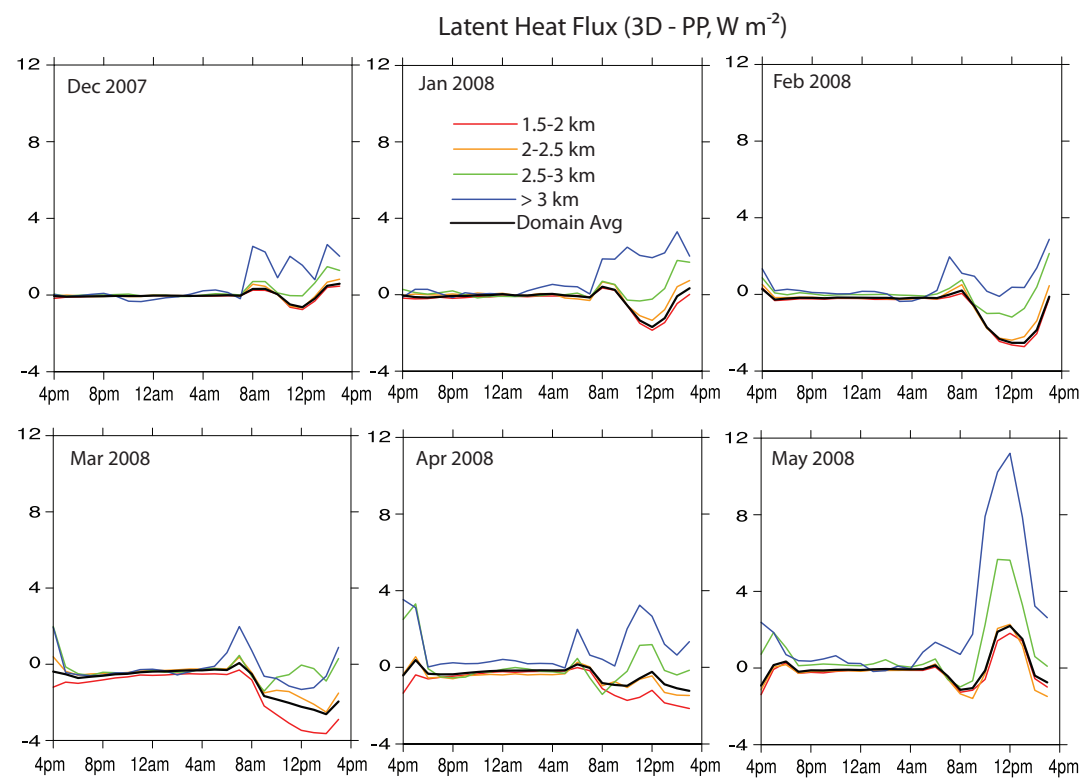

Fig. 7. Same as in Fig. 5, except for the monthly mean domain-averaged diurnal variation time series of latent heat flux.

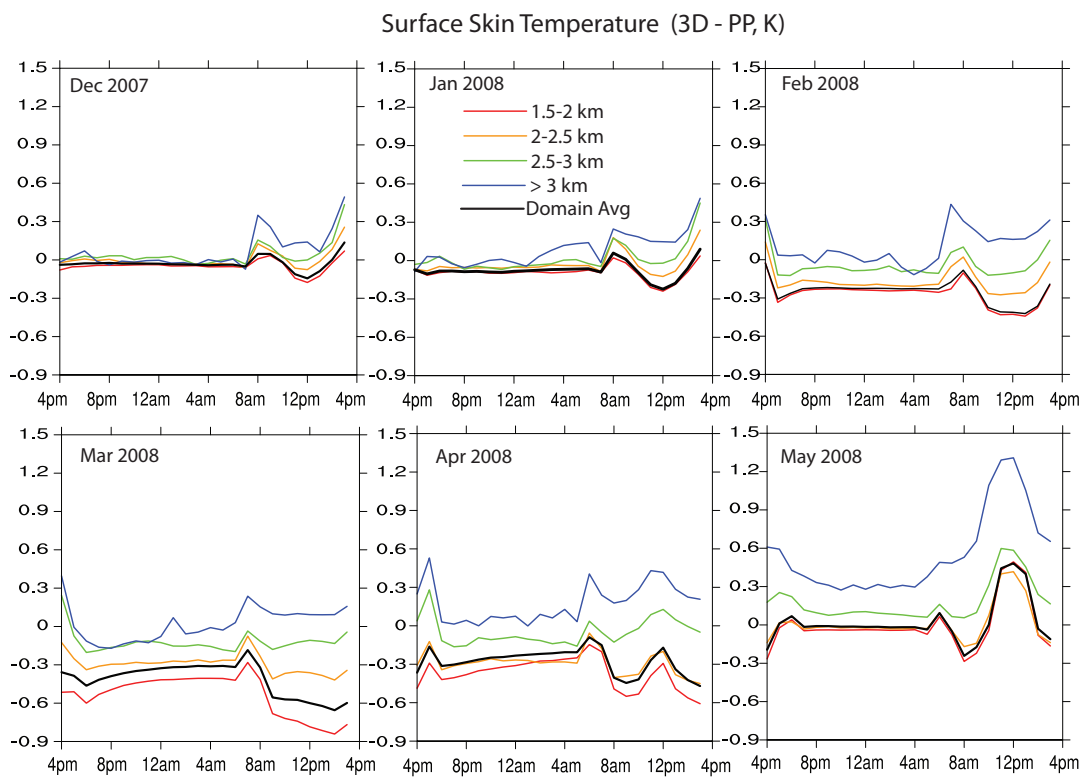

Fig. 8. Same as in Fig. 5, except for the monthly mean domain-averaged diurnal variation time series of surface skin temperature.

In Fig. 10a-d, we show deviations (3-D-PP) of the domain-averaged monthly net solar flux, which is defined as the downward solar flux multiplied by $(1-\bar{A})$, where $\bar{A}$ is the monthly surface albedo, sensible and latent heat fluxes, and surface skin temperature for a 7 month period as a function of elevation. For net solar, sensible heat, and latent heat fluxes over lower elevations $(<2.5 \mathrm{~km})$, negative deviations are shown, with the largest reduction occurring in March. Surface skin temperature largely follows the preceding flux patterns. For higher elevations $(>2.5 \mathrm{~km})$, positive deviations are seen, with a minimum between the months of February and March and substantial increases in deviations starting in March associated with the position of the sun. The monthly changes of the whole domain basically follow the pattern of lower elevation ranges $(<2.5 \mathrm{~km})$ which comprise $\sim 65 \%$ of the area mentioned previously.

The monthly averaged CWP $\left(\mathrm{g} \mathrm{m}^{-2}\right)$ over the entire domain simulated from the $3-\mathrm{D}$ experiment as a function of 


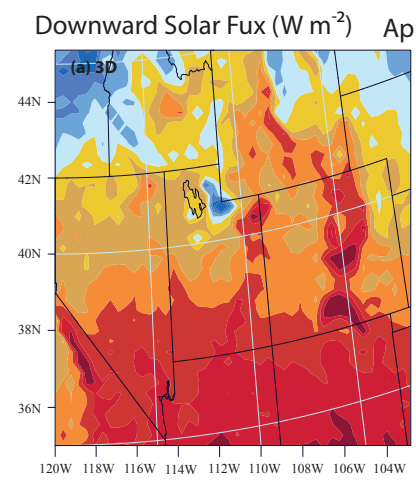

April 2008 Cloud Water Path $\left(\mathrm{g} \mathrm{m}^{-2}\right)$

$250260270280290 \quad 300310320330340$
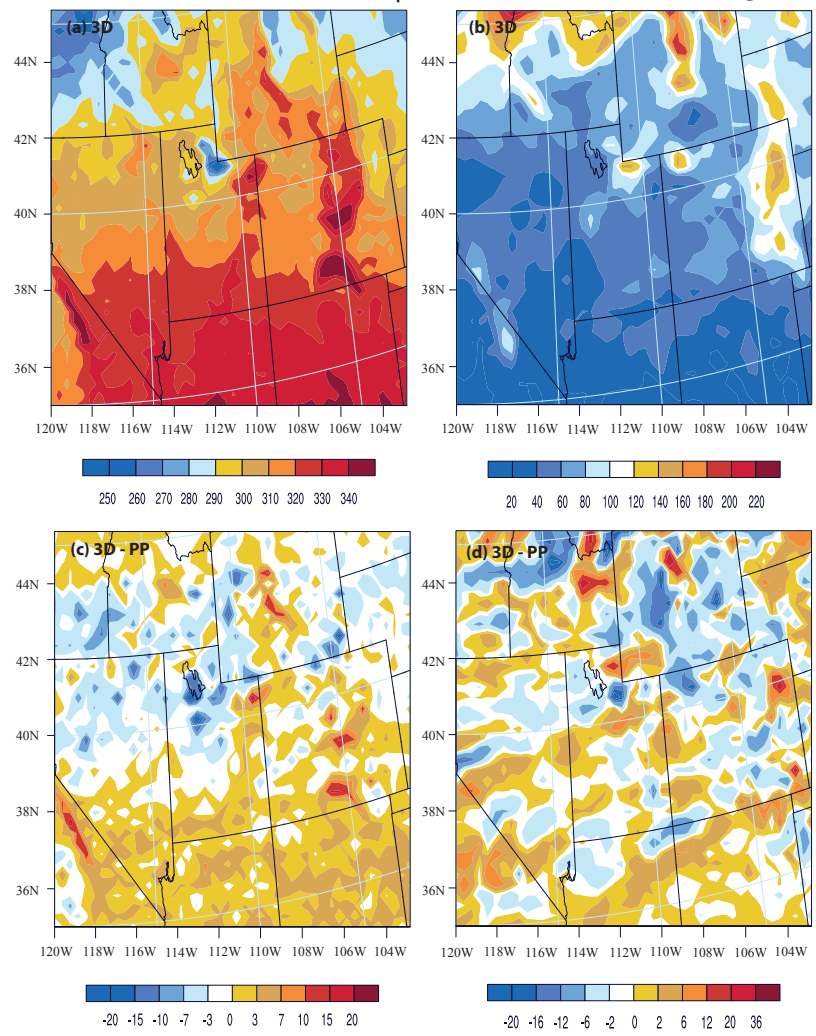

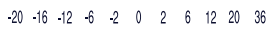

Fig. 9. (a) The monthly averaged surface solar flux $\left(\mathrm{W} \mathrm{m}^{-2}\right)$ map for April 2008 simulated for the 3-D case as a function of latitude and longitude. (b) The monthly averaged Cloud Water Path (CWP, $\mathrm{g} \mathrm{m}^{-2}$ ) map for April 2008 simulated for the 3-D case as a function of latitude and longitude. (c) The corresponding deviation (3-D-PP) map for downward solar flux. (d) The corresponding deviation (3D-PP) map for CWP.

elevation is illustrated in Fig. 11a. The corresponding deviations (3-D-PP) are displayed in Fig. 11b. The cloud water over the Rocky Mountains and Sierra Nevada regions appears to generally increase starting in November and, after reaching a maximum in January, decreases until April; subsequently, it shows a trend of increasing in May. From November to January, due to the 3-D mountain effect, CWP presents positive changes for the lowest elevation $(1.5-2 \mathrm{~km})$ and elevations $>3 \mathrm{~km}$. From January to April, negative deviations occur in all elevation areas. The monthly averaged cloud fraction (\%) is shown in Fig. 11c, with the associated deviations depicted in Fig. 11d. Their patterns generally follow those of CWP.

The monthly mean SWE (mm) averaged over the entire domain as a function of elevation is shown in Fig. 12a. The corresponding SWE deviations (3-D-PP) are displayed in Fig. 12d; these deviations show an increase in lower elevations, due to the mountain shading effect, with the largest value occurring in March. The positive deviations become
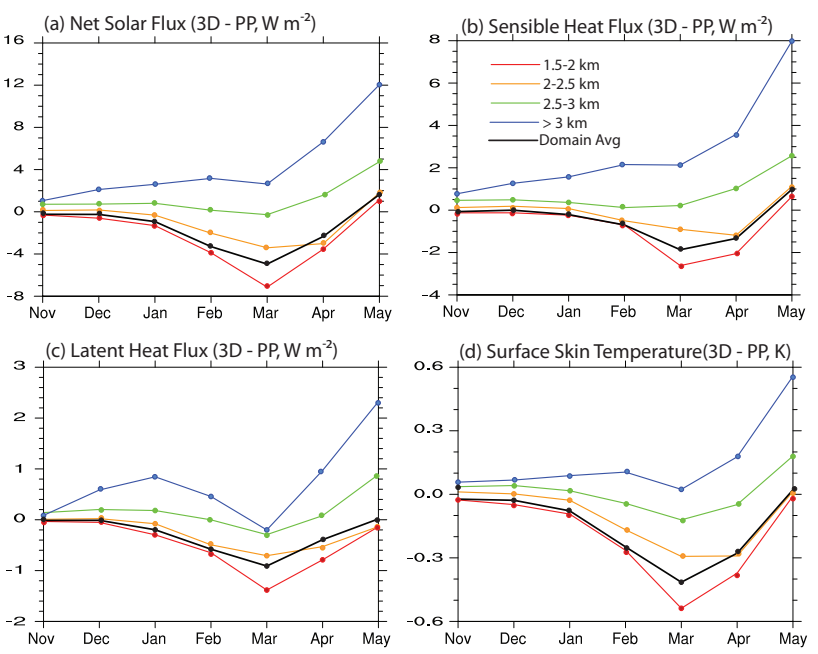

Fig. 10. Deviations (3-D-PP) of the domain-averaged monthly (a) net solar flux, (b) sensible heat flux, (c) latent heat flux, and (d) surface skin temperature for a 7-month period (November 2007-May 2008) as a function of elevation. 1.5-2 km (red), 2-2.5 km (orange), 2.5-3 $\mathrm{m}$ (green), above $3 \mathrm{~km}$ (blue), and the whole domain (black).

smaller after March because the Sun is more often overhead during the spring, leading to a reduced shading effect. As a result of increased snow accumulation that reduces rainfall and/or snowmelt contributions to runoff, the cumulative runoff deviations (3-D-PP) are reduced for lower elevation areas (Fig. 12f) with reference to the values produced from the 3-D mountain experiment displayed in Fig. 12c. Due to the mountain effect, SWE decreases over higher elevation areas in connection with greater solar radiation available at the surface. At the elevation range above $3 \mathrm{~km}$, SWE is reduced by $8 \%$ in April and by $24 \%$ in May due to 3-D effects. The cumulative runoff increases in February, and a maximum increase occurs in April for the elevation range 2.5$3 \mathrm{~km}$, while for elevations above $3 \mathrm{~km}$, the cumulative runoff values substantially increase after March because of the increased surface solar flux produced by the 3-D mountain effect, which leads to increased snowmelt runoff. The surface runoff is calculated from the simple water balance (SWB) model (Schaake et al., 1996). The snow model in the Noah land-surface model simulates the snow accumulation, sublimation, melting, and heat exchange at snow-atmosphere and snow-soil interfaces. The precipitation is categorized as snow when the temperature in the lowest atmospheric layer is below $0{ }^{\circ} \mathrm{C}$.

The monthly mean precipitation $(\mathrm{mm})$ as a function of elevation over the simulation domain is shown in Fig. 12b. Generally, precipitation increases with elevation due to orographic forcing - except above $3 \mathrm{~km}$, where moisture is significantly depleted due to rainout at the lower elevations. Precipitation increases from November to May, with substantially larger values for elevation areas higher than $2.5 \mathrm{~km}$. In 

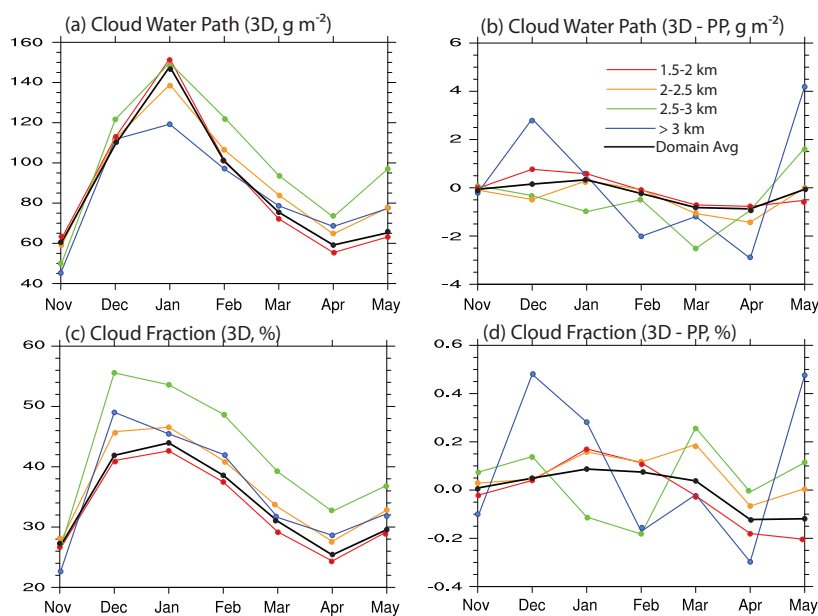

Fig. 11. (a) The monthly averaged Cloud Water Path (CWP, $\mathrm{g} \mathrm{m}^{-2}$ ) over the entire domain simulated from the 3-D experiment as a function of elevation. (b) The corresponding deviations (3-D-PP) for CWP. (c) The monthly averaged cloud fraction (\%) over the entire domain simulated from the 3-D experiment as a function of elevation. (d) The corresponding deviations (3-D-PP) for cloud fraction. $1.5-2 \mathrm{~km}$ (red), 2-2.5 km (orange), 2.5-3 m (green), above $3 \mathrm{~km}$ (blue), and the whole domain (black).

terms of deviations (3-D-PP), we see decreases in higher elevation areas, with a minimum occurring in April in relation to the CWP deviation result (Fig. 11b), which also contributes to SWE decrease. For lower regions, precipitation deviations (Fig. 12e) increase and result in the increased SWE in conjunction with the reduced runoff. Thus, one important impact of the 3-D mountain effect is to delay the snowmelt-driven runoff into the warm season for lower elevations and, at the same time, to reduce the SWE in higher elevation regions.

\section{Concluding remarks}

The 3-D radiative transfer parameterization developed for the computation of surface solar fluxes has been incorporated into the WRF model and applied at a resolution of $30 \mathrm{~km}$ over the Rocky Mountains and Sierra Nevada in the western United States. We have carried out simulations for a sevenmonth period from 1 November 2007 to 31 May 2008, during which snow accumulation was abundant, to understand the effect of 3-D mountains/snow on the diurnal and monthly variation of surface radiative and heat fluxes and the consequence of snowmelt and precipitation at different elevations. The monthly mean SWE values from the WRF simulation with 3-D radiation are generally comparable in spatial pattern and seasonality to the CMC and SNOTEL data, in view of the relatively coarse resolution of $30 \mathrm{~km}$ compared to the $4 \mathrm{~km}$ resolution used for the WRF simulations presented by Rasmussen et al. (2011), our simulated SWE is high in magnitude. This is confirmed by comparing our simulated pre- cipitation at high elevation zones (higher than $2.5 \mathrm{~km}$ ) with SNOTEL data, which are also obtained at high elevations. Nevertheless, our simulations captured the spatial pattern, elevation dependence, and daily/seasonal variability of precipitation and snowpack sufficiently well to provide confidence for investigating the impacts of 3-D radiation associated with mountains/snow on the surface hydrology of the western United States. Key findings are summarized as follows.

First, deviations of the monthly mean surface solar flux produced by 3-D mountain effects compared to PP results over the Rocky Mountains and Sierra Nevada regions are a function of elevation and time of the day. During winter, positive deviations up to $10 \mathrm{~W} \mathrm{~m}^{-2}$ are found in the morning from 07:00-10:00 as well as in the afternoon from 14:00-17:00 due to shading effects for areas at elevations below $2.5 \mathrm{~km}$. The maximum negative deviation occurs in the lower elevation from 1.5-2 km around noon in February with a value of $\sim 30 \mathrm{~W} \mathrm{~m}^{-2}$. During spring, positive deviations shifts to earlier morning (between 06:00-08:00), while negative deviations begin to occur at 08:00. Over the mountaintops above $3 \mathrm{~km}$, positive deviations are found throughout the day, indicating that more solar fluxes are found in this region in association with longer daylight hours. The maximum positive deviation is found around noon in May, with a value of $\sim 60 \mathrm{~W} \mathrm{~m}^{-2}$.

Second, deviations in the surface solar radiation field can affect latent and sensible heat fluxes, and the changes in the surface energy balance are reflected in changes in surface skin temperature. Changes in the seasonal sensible and latent heat fluxes as functions of local time and elevation primarily follow net solar flux patterns. Also, negative (winter) and positive (spring) deviations in sensible/latent heat fluxes become smaller in magnitude around noon. The deviations in sensible heat flux are generally greater than those of latent heat flux, which reflect the Bowen ratio in the semi-arid western United States. In May, we obtained a maximum of $\sim 30 \mathrm{~W} \mathrm{~m}^{-2}$ around noon for sensible heat flux compared to $\sim 10 \mathrm{~W} \mathrm{~m}^{-2}$ for latent heat flux. Deviations in the surface skin temperature, which largely follows the diurnal net solar flux pattern, displays cooling for elevations below $2.5 \mathrm{~km}$ due to shading effects. For mountaintop regions (> $3 \mathrm{~km}$ ), warming is found throughout the day for both winter and spring.

Third, the monthly SWE deviations averaged over the entire domain show an increase in lower elevations due to the mountain shading effect, which produces the largest value in March (a $15 \%$ increase at the lowest elevation range of $1.5-2 \mathrm{~km}$ ). Positive deviations become smaller during other spring months in connection with the position of overhead sun. The cumulative runoff is subsequently reduced in lower elevation areas from February to May due to the mountain effect that reduces snowmelt. By contrast, over higher elevation areas, SWE decreases by $8-24 \%$ in April and May in connection with more solar radiation being available at the surface. As a result of increased snowmelt, the cumulative 


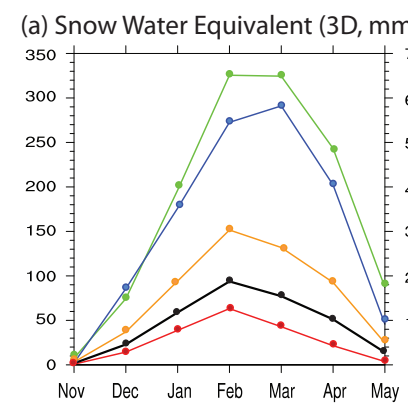

(b) Precipitation (3D, mm) (c) Cumulative Runoff (3D, mm)

(d) Snow Water Equivalent (3D - PP, mm) (e) Precipitation (3D - PP, mm) (f) Cumulative Runoff (3D - PP, mm)

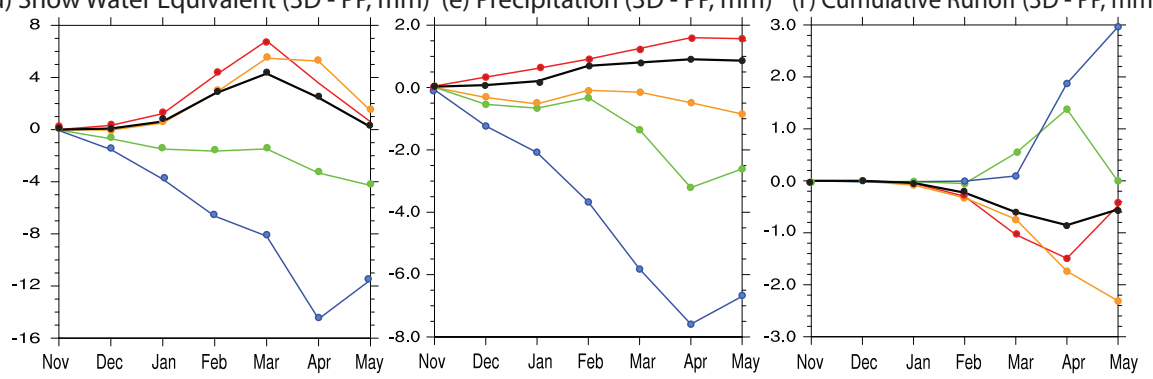

Fig. 12. (a) The monthly mean snow water equivalent (SWE, mm) averaged over the simulation domain as a function of elevation. (b) The monthly mean precipitation $(\mathrm{mm})$ averaged over the simulation domain as a function of elevation. (c) The monthly mean cumulative runoff averaged over the simulation domain as a function of elevation. (d) The corresponding SWE deviations (3-D-PP). (e) The correspondence precipitation deviations (3-D-PP). (f) The correspondence runoff deviations (3-D-PP). 1.5-2 km (red), 2-2.5 km (orange), 2.5-3 m (green), above $3 \mathrm{~km}$ (blue), and the whole domain (black).

runoff increases in spring, with a maximum increase occurring in April for the elevation range $2.5-3 \mathrm{~km}$. At the mountaintops above $3 \mathrm{~km}$, the cumulative runoff values substantially increase after March; this is associated with the increased surface solar flux produced by the 3-D mountain effect, leading to increased snowmelt runoff. Precipitation decreases from November to May, with substantially larger deviations at elevations higher than $2.5 \mathrm{~km}$. For lower elevation regions, precipitation increases and contributes to the increased SWE due to shading effects. Thus, an important impact of the 3-D mountain effect is to enhance (reduce) the SWE in lower (higher) elevation regions, while concurrently shifting the runoff seasonality through changes in snowmelt.

Overall, this study shows that deviations of SWE due to $3-\mathrm{D}$ radiation effects range from an increase of $18 \%$ at the lowest elevation range $(1.5-2 \mathrm{~km})$ to a decrease of $8 \%$ at the highest elevation range $(>3 \mathrm{~km})$ during the snowmelt season of April to May. Because lower elevation areas occupy larger fractions of the land surface, the net effect of 3-D radiation is to extend snowmelt and snowmelt-driven runoff into the warm season. The redistribution of SWE across different elevations and the shift in runoff timing have important implications to cold season surface hydrology that may extend through the warm season due to changes in soil moisture and evapotranspiration. Since about $60-90 \%$ of water resources worldwide originate from mountains, the aforementioned differences in simulated hydrology due solely to 3-D interactions between solar radiation and mountains merit further investigation in order to understand the implications to modeling mountain water resources and their vulnerability to climate change and air pollution.

In this study, we have focused on analysis involving the interactions between solar radiation and surface energy and water budgets by means of elevation bands. As a follow-up study, we plan to investigate the 3-D mountain orientation effect on the distributions of surface solar and heat fluxes, SWE, runoff, and precipitation based on the simulations presented above. It would also be interesting to study surface hydrological patterns in relation to the 3-D mountain radiation effect in the summer months to investigate how changes in surface energy and hydrology associated with SWE, runoff, and soil moisture influence evapotranspiration patterns in the summer, as well as how diurnal deviations of solar radiation due to mountains influence convection and the diurnal timing and amount of precipitation. Finally, we plan to employ the $90 \mathrm{~m}$ topographical data available from the Shuttle Radar Topography Mission (SRTM) to construct an improved radiation parameterization that can be applied to model resolutions higher than $10 \mathrm{~km}$ in future studies. 
Acknowledgements. This research was supported by the Office of Science of the US Department of Energy as part of the Earth System Modeling program through DOE Grant DESC0006742 to UCLA and separate funding to PNNL. PNNL is operated for DOE by Battelle Memorial Institute under contract DE-AC05-76RLO1830.

Edited by: Q. Fu

\section{References}

Beljaars, A. C. M.: The parameterization of surface fluxes in largescale models under free convection, Q. J. Roy. Meteor. Soc., 121, 255-270, 1994.

Bonan, G. B.: Ecological Climatology: Concepts and Applications, Cambridge Univ. Press, New York, USA, 678 pp., 2002.

Brown, R. D. and Brasnett, B.: Canadian Meteorological Centre (CMC) Daily Snow Depth Analysis Data, Environment Canada, 2010, Boulder, CO, USA, National Snow and Ice Data Center (updated annually), 2010.

Chen, F. and Dudhia, J.: Coupling an advanced land surface - hydrology model with the Penn State - NCAR MM5 modeling system. Part I: Model implementation and sensitivity, Mon. Weather Rev., 129, 569-585, 2001.

Chen, Y., Hall, A., and Liou, K. N.: Application of threedimensional solar radiative transfer to mountains, J. Goephys. Res., 111, D21111, doi:10.1029/2006JD007163, 2006.

Daly, C., Neilson, R. P., and Phillips, D. L.: A statisticaltopographical model for mapping climatological precipitation over mountainous terrain, J. Appl. Meteor., 33, 140-158, 1994.

Dyer, A. J. and Hicks, B. B.: Flux-gradient relationships in the constant flux layer, Q. J. Roy. Meteor. Soc., 96, 715-721, 1970.

$\mathrm{Fu}, \mathrm{Q}$. and Liou, K. N.: On the correlated $k$-distribution method for radiative transfer in nonhomogeneous atmospheres, J. Atmos. Sci., 49, 2139-2156, 1992.

Fu, Q. and Liou, K. N.: Parameterization of the radiative properties of cirrus clouds, J. Atmos. Sci., 50, 2008-2025, 1993.

Geiger, R.: The Climate Near the Ground, Harvard Univ. Press, Cambridge, USA, 611 pp., 1965.

Gu, L., Baldocchi, D., Verma, S. B., Black, T. A., Vesala, T., Falge, E. M., and Dowty, P. R.: Advantages of diffuse radiation for terrestrial eco-system productivity, J. Geophys. Res., 107, 4050, doi:10.1029/2001JD001242, 2002.

Gu, Y., Liou, K. N., Chen, W., and Liao, H.: Direct climate effect of black carbon in China and its impact on dust storms, J. Geophys. Res., 115, D00K14, doi:10.1029/2009JD013427, 2010.

Gu, Y., Liou, K. N., Ou, S. C., and Fovell, R.: Cirrus cloud simulations using WRF with improved radiation parameterization and increased vertical resolution, J. Geophys. Res., 116, D06119, doi:10.1029/2010JD014574, 2011.

Gu, Y., Liou, K. N., Lee, W.-L., and Leung, L. R.: Simulating 3-D radiative transfer effects over the Sierra Nevada Mountains using WRF, Atmos. Chem. Phys., 12, 9965-9976, doi:10.5194/acp-129965-2012, 2012.

Hong, S.-Y., Noh, Y., and Dudhia, J.: A new vertical diffusion package with an explicit treatment of entrainment processes, Mon. Weather Rev., 134, 2318-2341, 2006.

Kain, J. S. and Fritsch, J. M.: A one-dimensional entraining/detraining plume model and its application in convective parameterization, J. Atmos. Sci., 47, 2784-2802, 1990.
Kain, J. S. and Fritsch, J. M.: Convective parameterization for mesoscale models: the Kain-Fritcsh scheme, in: The Representation of Cumulus Convection in Numerical Models, edited by: Emanuel, K. A. and Raymond, D. J., Amer. Meteor. Soc., 246 pp., 1993.

Kapnick, S. and Hall, A.: Observed climate-snowpack relationships in California and their implications for the Future, J. Climate, 23, 3446-3456, 2010.

Koren, V., Schaake, J., Mitchell, K., Duran, Q. Y., Chen, F., and Baker, J. M.: A parameterization of snowpack and frozen ground intended for NCEP weather and climate models, J. Geophys. Res., 104, 19569-19585, 1999.

Lee, W. L., Liou, K. N., and Hall, A.: Parameterization of solar fluxes over mountain surfaces for application to climate models, J. Geophys. Res., 116, D01101, doi:10.1029/2010JD014722, 2011.

Lee, W. L., Liou, K. N., and Wang, C.: Impact of 3-D topography on surface radiation budget over the Tibetan Plateau, Theor. Appl. Climatol., 113, 95-103, doi:10.1007/s00704-012-0767-y, 2012.

Leung, L. R., Qian, Y., and Bian, X.: Hydroclimate of the western United States based on observations and regional climate simulation of 1981-2000. Part I: Seasonal statistics, J. Climate, 16, 1892-1991, 2003a.

Leung, L. R., Qian, Y., Bian, X., and Hunt, A.: Hydroclimate of the western United States based on observations and regional climate simulation of 1981-2000. Part II: Mesoscale ENSO anomalies, J. Climate, 16, 1912-1928, 2003b.

Leung, L. R., Qian, Y., Bian, X., Washington, W. M., Han, J., and Roads, J. O.: Mid-century ensemble regional climate change scenarios for the western United States, Clim. Change, 62, 75-113, 2004.

Lin, Y.-L., Farley, R. D., and Orville, H. D.: Bulk parameterization of the snow field in a cloud model, J. Climate Appl. Meteorol., 22, 1065-1092, 1983.

Liou, K. N., Lee, W.-L., and Hall, A.: Radiative transfer in mountains: Application to the Tibetan Plateau, Geophys. Res. Lett., 34, L23809, doi:10.1029/2007GL031762, 2007.

Müller, M. D. and Scherer, D.: A grid- and subgrid-scale radiation parameterization of topographic effects for mesoscale weather forecast models, Mon. Weather Rev., 133, 1431-1442, 2005.

Paulson, C. A.: The mathematical representation of wind speed and temperature profiles in the unstable atmospheric surface layer, J. Appl. Meteorol., 9, 857-861, 1970.

Qian, Y., Gustafson, W. I., Leung, L. R., and Ghan, S. J.: Effects of soot-induced snow albedo change on snowpack and hydrological cycle in western US based on WRF chemistry and regional climate simulations, J. Geophys. Res., 114, D03108, doi:10.1029/2008JD011039, 2009.

Rasmussen, R. M., Liu, C., Ikeda, K., Gochis, D., Yates, D., Chen, F., Tewari, M., Barlage, M., Dudhia, J., Yu, W., Miller, K., Arsenault, K., Grubistic, V., Thompson, G., and Gutmann, E.: Weather Support to Deicing Decision Making (WSDDM): a winter weather nowcasting system, Bull. Amer. Meteorol. Soc., 82, 579-595, 2011.

Schaake, J. C., Koren, V. I., Duan, Q. Y., Mitchell, K., and Chen, F.: A simple water balance model (SWB) for estimating runoff at different spatial and temporal scales, J. Geophys. Res., 101, 7461-7475, 1996. 
Skamarock, W. C., Klemp, J. B., J. Dudhia, J., Gill, D. O., Barker, D. M., Wang, W., and Powers, J. G.: A description of the Advanced Research WRF Version 2, NCAR Tech. Note 468+STR, Natl. Cent. for Atmos. Res., Boulder, CO, USA, 88 pp., 2005.

Skamarock, W. C., Klemp, J. B., Dudhia, J., Gill, D. O., Barker, D. M., Wang, W., and Powers, J. G.: A description of the Advanced Research WRF Version 3, NCAR Tech. Note 475+STR, Natl. Cent. for Atmos. Res., Boulder, CO, USA, 125 pp., 2008.
Taylor, G., Daly, C., Gibson, W., and Sibul-Weisburg, J.: Digital and Map Products Produced Using PRISM, 10th Conf. on Applied Climatology, Reno, NV, Amer. Meteor. Soc., 217-218, 1997.

Webb, E. K.: Profile relationships: The log-linear range and extension to strong stability, Q. J. Roy. Meteor. Soc., 96, 67-90, 1970.

Zhang, D.-L. and Anthes, R. A.: A high-resolution model of the planetary boundary layer- sensitivity tests and comparisons with SESAME - 79 data, J. Appl. Meteorol., 21, 1594-1609, 1982. 